The Prognosis of Patients with Epilepsy. By ERnst A. Rodin. (Pp. xii $+455 ; 24$ figures +118 tables and Appendix. \$19.50.) Springfield, Illinois; Charles C. Thomas. 1969.

Epilepsy. By William Pryse-Phillips. (Pp. viii + 96; 12 figures +3 tables. 18s.) Bristol: John Wright. 1969.

About $7 \%$ of children have one or more convulsions. The most urgent questions their parents ask are concerned with prognosis, and Dr. Rodin's book (though not confined to fits in childhood) attempts to supply the answers. It has two main sections. The first reviews the literature clearly and thoroughly, and contains a great deal of really valuable information. Each chapter begins by formulating the relevant questions and ends by summarizing the answers. We learn, for example, that about half the infants who have a simple febrile convulsion will have at least one recurrence, and that there is no evidence that the incidence of recurrences is reduced by either continuous or intermittent anticonvulsant therapy.

The second section tries to repair the gaps and deficiencies in the literature by describing the author's own investigations at the Michigan Epilepsy Centre. The questions are formulated differently from those put in the first section, and the facts are difficult to disentangle from the statistical methods used in their analysis. There are no chapter summaries in this section, and one is left with the impression of a wealth of useful but somewhat inaccessible information.

Despite the disappointment of the second section, this book provides information of value to every paediatrician. It is a pity it is so expensive.

Dr. Pryse-Phillips's book is an attractively produced monograph in soft covers at a very reasonable price. It attempts in less than 100 pages to summarize the whole subject of epilepsy, including the neuro-physiology, classification, aetiology, clinical features, use of the EEG, and social and psychiatric management. It seems too long for the medical student, and on the whole not authoritative enough for anyone else. It cannot be wholeheartedly recommended to paediatricians, since fits in childhood are dealt with perfunctorily and somewhat inaccurately. For example, the causes of neonatal fits mentioned do not include hypocalcaemia, and hypoglycaemia is said to be 'not uncommon when the child was premature'. The section on the EEG is perhaps the best, giving a clear short summary of what it may show and how it may help in the management of epilepsy.

\section{2nd European Congress of Perinatal Medicine}

The 2nd European Congress of Perinatal Medicine, sponsored by the European Association of Perinatal Medicine, will be held in London from April 8-10, 1970.

There will be three sessions devoted to the following symposia: Assessment and Management of the Fetus at Risk; Low Birthweight; Immunology and Infection. There will be adequate time for free discussion. Two sessions will consist of papers submitted by individuals.

For further information please write to The Congress Office, 2nd European Congress of Perinatal Medicine, The Conference Centre, 43 Charles Street, Mayfair, London W.1.

\section{Erratum}

A Screening Method for Liver Glycogen Diseases, by J. Fernandes, F. Huijing, and J. H. van de Kamer. p. 312, Table; bottom of column headed 'Remarks', for 'Brother of Case 7', please read 'Brother of Case 17'. 